Б. В. Мисник, старший викладач, e-mail: setne1985@gmail.com.

Т. І. Веретільник, к.т.н., професор, e-mail: vertim@mail.ua

Л. Д. Мисник, к.т.н., доиент, e-mail: l.mysnyk@chdtu.edu.ua

Черкаський державний технологічний університет

Бул. Шевченка, 460, м. Черкаси, 18006, Україна

\title{
МУЛЬТИАГЕНТНА ОПТИМІЗАЦІЯ ФУНКЦІОНУВАННЯ ТА ПІДТРИМКА ПРОЦЕСІВ ПРИЙНЯТТЯ РІШЕНЬ КЕРІВНИКОМ ПІДПРИЕМСТВА ПОЛІГРАФІЧНОЇ ГАЛУЗІ
}

Розглянуто задачу аналізу та оптимізаиії функиіонування підприємства галузі. Запропоновано як інструментарій моделювання та підтримки прийняття рішень використовувати мультиагентні технології. Визначено проблеми, які супроводжують прочес моделювання, побудовано моделі з використанням продукиійних правил та розроблено метод оптимізаиії на основі зміни множини задач, структури виробництва та стратегії управління підприємством.

Ключові слова: підприємство галузі, прийнятття рішень, мультиагентні технологї̈.

\section{Постановка проблеми}

Як відомо, галузь утворюють підприємства, що випускають однорідну продукцію. У більшості випадків вони є невеликими конкуруючими виробництвами або інфраструктурними об'єктами, наприклад, інтернетмагазинами, будівельними фірмами, підприємствами з виробництва меблів, вікон тощо. Процеси їх створення, функціонування, модернізації, розширення чи ліквідації вимагають аналітичної підтримки.

\section{Аналіз останніх досліджень}

Раніше, в роботах $[1,2]$, розглядались аспекти моделювання діяльності таких підприємств та застосування 3 цією метою мультиагентних систем, наголошувалось на значній невизначеності таких процесів, що пов'язано із інкапсуляцією окремими суб'єктами галузі даних про характеристики виробництва та їх динаміку. Невідповідність між необхідністю одержання даних та небажанням надавати аналогічну інформацію становить проблему як для ринку взагалі, так і для конкретної особи, що приймає рішення (ОПР), зокрема.

Розглянемо проблему супроводу підприємств галузі по етапах їх життєвого циклу та використаємо для іiі рішення елементи теорії мультиагентних систем (МАС). Джерело теорії МАС можливо відслідкувати в книзі
[3], виданій за матеріалами однієї з конференцій в Празі у 2001 році. Головними питаннями, що обговорювалося на конференції, були: перспективи організації МАС, мультиагентна інфраструктура, логічні засади МАС, стандартизація комунікації в МАС, прийняття рішень в МAC, команди гетерогенних агентів. Очевидно, що на конференції розглядалися теоретичні задачі розвитку МАС, розробки відповідних моделей та методів. Зміни, що відбулися 3 того часу, відображені в матеріалах конференції 2013 року в Іспанії. Тут головними стати технології використання МАС для рішення практичних задач, зокрема використання MAC в Grid, в віртуальних організаціях, при представленні транспортних сервісів, для складання логічного розкладу, для розробки рекомендаційних систем, в енергетиці, в медицині та ін. Динаміка МАC: від теорії до практики свідчить про актуальність використання такого виду систем та про раціональність їх розробки та використання.

На користь останнього припущення свідчать і роботи вітчизняних вчених. Наприклад, дослідженні можливості побудови логічних інформаційних систем на підприємствах, що здатні забезпечити організаційноекономічну стійкість підприємств в ринкових умовах 3 використанням економіко- 
математичного моделювання і інформаційних технологій, результатом чого є розроблені MAC [3]. Створювалися МАC і для рішення задач моделювання розвитку міської інфраструктури 3 ціллю отримання загальної картини шляхом об'єднання окремих задач, що вирішуються в межах окремих агентів. Розроблена технологія сумісного використання мультиагентного імітаційного моделювання і експертних оцінок для прогнозування еволюційного розвитку міста [4]. Пропонувалися технології розробки МАС від визначення вимог до реалізації з використанням трансформаційних процесів інтелектуальних агентів, що дозволяло генерувати нечіткі платформонезалежні моделі внутрішнього управління агентами [5]. Розглядалися інформаційні моделі управління процесом [6] навчання 3 використанням мультиагентного підходу в умовах адаптивного навчання, що створює засади повної автоматизації управління процесом навчання [7,8]. Ми проаналізували тільки малу частину галузей і методів, де доведені переваги використання МАС. Ще однією задачею, де $\epsilon$ потреба у використанні принципів створення і функціонування МАС, є прийняття рішень на підприємствах галузі.

Метою дослідження $€$ визначення основних функцій, можливостей та проблем функціонування мультиагентних систем підтримки прийняття рішень керівником підприємства галузі.

\section{Постановка задачі}

Керівник кожного підприємства в процесі його функціонування неминуче стикається 3 необхідністю прийняття рішень про модернізацію, ліквідацію, зміну спектру вирішуваних завдань, структури виробництва, стратегії управління, в більшості випадків полягає в розподілі ресурсів. Різні передумови, масштаби прийнятих рішень та їх наслідки притаманні підприємствам-монополістам і підприємствам галузі, випускаючим однорідну продукцію. Якщо монополіст орієнтується на зовнішню кон'юнктуру, особливості законодавства, постачальників та споживачів як деякі абстрактні сукупності великої потужності, то керівник підприємства галузі орієнтується на мікроекономічні параметри, особливості функціонування підприємств, що, в деяких випадках, знаходяться у відношеннях кооперації, але частіше виявляються конкурентами. В ідеальному випадку ОПР-керівник підприємства оптимізує його діяльність, враховуючи середню ціну продукції на ринку і в кожного підприємства-конкурента зокрема, а також інші показники ефективності (собівартість, фондоозброєність та ін.). Обмежуючим фактором є ємність ринку, а направляючим фактором - закон рівності попиту та пропозиції.

Враховуючи, що функціонування підприємства (виготовлення продукції) можна вважати процесом неперервним, а транзакції (продаж продукції, закупка матеріалів, отримання інвестицій та ін.) відбуваються в дискретні проміжки часу, його діяльність можливо представити деяким неперервнодискретним або логіко-динамічним процесом.

Особа, що приймає рішення, на підставі знань, досвіду та інтуїції, визначає стратегію і тактику розвитку підприємства, але в більшості випадків його діяльність є оперативною реакцією на поточний стан навколишнього середовища та значень параметрів підприємства [9]. Критичність впливу фактору часу призводить до невірних або стратегічно провальних рішень. Їх негативні наслідки можливо було б виключити використовуючи прогнозування і аналіз можливих сценаріїв розвитку подій. Відповідним інструментарієм можуть бути МАС. Агентом, в даному випадку, є деяка сутність, що призначена для автономного прийняття рішень, а також для підтримки прийняття рішень ОПР (рис. 1). Кожний агент має внутрішню структуру (міжмодульні зв'язки), елементний базис (програмні модулі для рішення окремих задач), використовує дані (як внутрішні для підприємства, так і з загальної бази даних), виконує заключення (на основі продукційних правил як приватних для підприємства, так і з загальної бази даних). Зауважимо, що метою функціонування агенту $є$ отримання максимального прибутку як рішення однієї з задач різними методами, так і висування рекомендацій щодо модифікації функціонування підприємства. Виконаємо формалізацію задачі оптимізації діяльності підприємства галузі. 


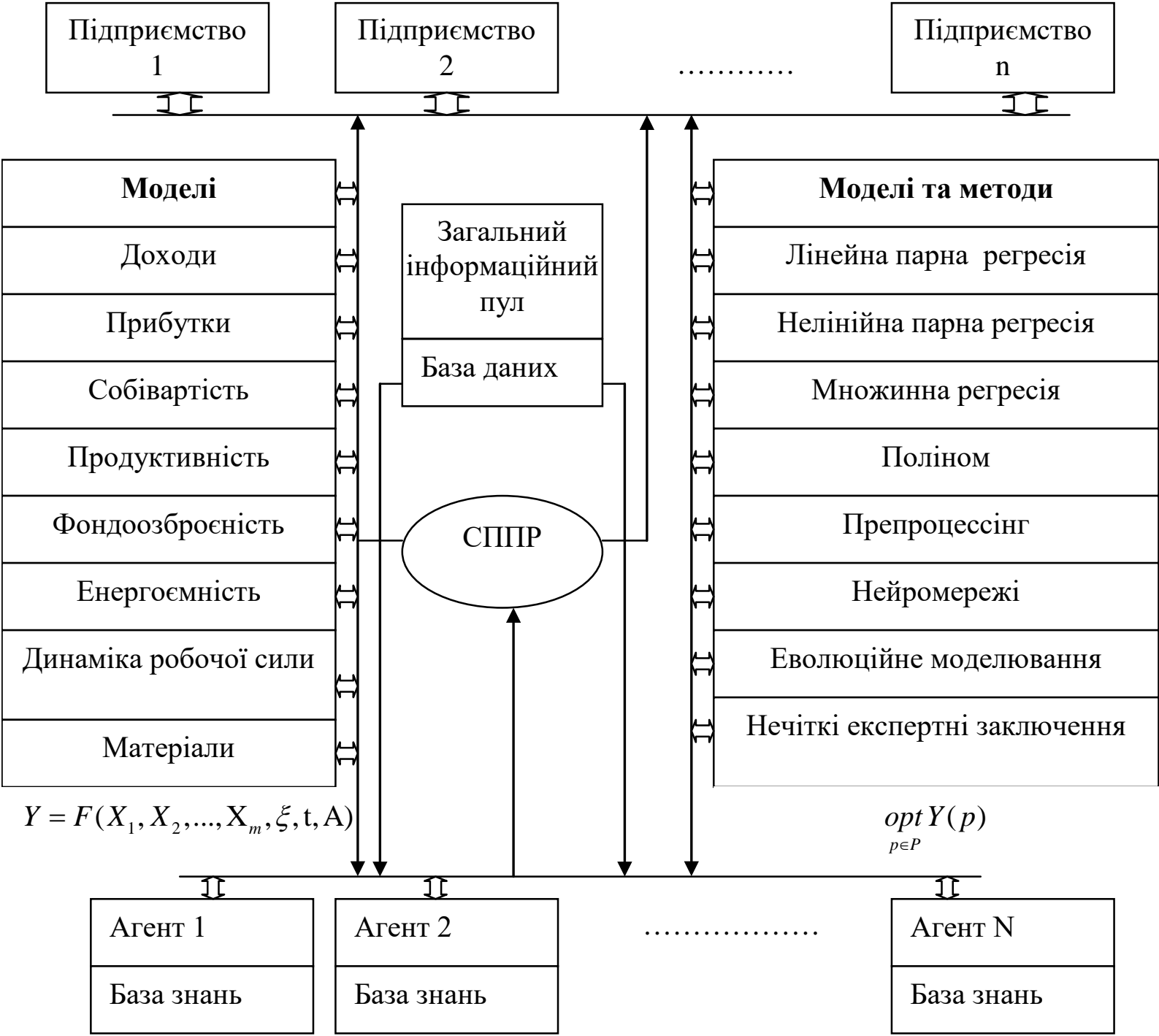

Рис. 1. Структура системи підтримки прийняття рішень з використанням мультиагентних систем

Нехай $S=\left\{S_{1}, S_{2}, \ldots, S_{n}\right\}$ - множина пі- функціонування підприємства $S_{i}$ визначаєтьдприємств галузі, $n \geq 2$. Будемо вважати, що ся трійкою елементів

$$
S_{i}=<X_{i}, Y_{i}, Z_{i}, t>\text {, }
$$

де $X_{i}$ - вхідні фактори системи, $Z_{i}$ - параметри внутрішнього стану, $Y_{i}-$ вихідні харак$S_{i}$ в момент часу $t$ визначається значеннями теристики системи $S_{i}, t$ - час. Стан системи

$$
S_{i}=<x_{i t}^{1}, x_{i t}^{2}, \ldots, x_{i t}^{n_{x}}, \mathrm{z}_{i t}^{1}, \mathrm{z}_{i t}^{2}, \ldots, \mathrm{z}_{i t}^{n_{z}}, \mathrm{y}_{i t}^{1}, \mathrm{y}_{i t}^{2}, \ldots, \mathrm{y}_{i t}^{n_{y}}>
$$

де $x_{i t}^{j}$ - значення $j$-го вхідного фактору в $\quad$ го на підприємство), $j=\overline{1, n_{x}} ; z_{i t}^{j}-$ значення момент часу $t$ (ціна обладнання, доставлено- $j$-го внутрішнього параметру (собівартість 
одиниці продукції), $j=\overline{1, n_{z}} ; y_{i t}^{j}-$ значення j-ї вихідної характеристики (дохід від продажу одиниці продукціï), $j=\overline{1, n_{y}}$. Будемо вважати будь-які зміни будь-якого значення 3 (2) транзакціями. Моменти часу, коли відбуваються транзакції, дискретизують часовий інтервал функціонування підприємства $T=\left\{t_{0}<t_{1}<t_{2}<\ldots\right\}$.

Вихідні характеристики підприємства або їх комбінації здійснюють вплив на функціонування підприємства i ефективність ऑiі реалізації оцінюється показником ефективності $P_{i}^{k}$, тобто

$$
P_{i}^{k}=P_{i}^{k}\left(S_{i}\right)=P_{i}^{k}\left(Y_{i}\right)=P_{i}^{k}\left(y_{i t}^{1}, y_{i t}^{2}, \ldots, y_{i t}^{n_{y}}\right),
$$

де $k=\overline{1, l}, l-$ кількість показників ефективльний критерій ефективності підприємства представимо так ності. Тоді інтегральний показник - інтегра-

$$
E_{i}=E_{i}\left(P_{i}^{1}, P_{i}^{2}, \ldots, P_{i}^{l}\right)=E_{i}\left(P_{i}^{1}\left(Y_{i}\right), P_{i}^{2}\left(Y_{i}\right), \ldots, P_{i}^{l}\left(Y_{i}\right)\right) .
$$

В свою чергу, $Y_{i}=F_{i}\left(X_{i}, Z_{i}\right)$, тому

$$
E_{i}=E_{i}\left(P_{i}^{1}\left(F_{i}\left(X_{i}, Z_{i}\right)\right), P_{i}^{2}\left(F_{i}\left(X_{i}, Z_{i}\right)\right), \ldots, P_{i}^{l}\left(F_{i}\left(X_{i}, Z_{i}\right)\right)\right) .
$$

Враховуючи те, що ринок продукції, що виробляється підприємством галузі має обмежену ємність, максимальний прибуток $E_{\max }$ могло б отримати єдине підприємство на ринку за відсутності конкуренції, наявності достатньої ресурсної та кадрової бази. Оскільки раніше така ситуація виключена $(n \geq 2)$, тоді для кожного підприємства вирішується задача $E_{i} \rightarrow E_{i \max } \forall t \in T$, де $T$ - інтервал часу функціонування підприємства.

Особливості ідентифікації показників ефективності підприємства

Звузимо нашу задачу і припустимо, що необхідно не проводити моделювання функціонування всіх підприємств галузі і ринку їх продукції, а діяти в інтересах одного підприємства $S_{*}$ і отримати рішення, що максимізує його ефективність і ініціює його структурну перебудову. ОПР буде враховувати ретроспе- ктивну інформацію, поточні стан та дії, прогнозуючи майбутнє.

Як зазначено на рис. 1, основою для прийняття рішень $\epsilon$ процес моделювання. Першочергово необхідно отримати моделі $P_{i}^{k}, k=\overline{1, l}$. Їх побудова починається з специфікації або структурної ідентифікації з використання банку моделей (лінійної та нелінійної парної регресії, лінійної та нелінійної множинної регресії, поліномів КолмогороваГабора, нейромереж, деревовидних структур та ін.). Параметрична ідентифікація таких моделей здійснюється 3 використанням відомих методів (найменших квадратів, групового врахування аргументів (МГВА), Бранлона, back propagation, генетичного програмування та ін.).

Рішення задач структурної і параметричної ідентифікації відбувається на основі інформації з баз даних, яка зберігається і записується в формату

$$
D B_{1}=<t_{i}, S_{j}>
$$

де $t_{i}$ - час транзакції, $S_{j}$ - значення параметрів j-го підприємства, що здійснювало транзакцію, у вигляді (2). Для скорочення кількості майбутніх розрахунків базі даних ставиться у відповідність база даних $D B_{2}$, виконуючи правило
Якщо $D B_{1} q_{j t-1}^{l}=q_{j t}^{l}$, то в $D B_{2} q_{j t}^{l}=$ ", де $q_{j t}^{l}$ - значення параметра $j$-ї системи в момент часу $t, l=\overline{1, n_{x}+n_{z}+n_{y}}, j=\overline{1, n}$.

Ідентифікація моделей буде здійснюватися на основі ретроспективної інформа- 
ціï, їх якість перевірятися 3 використанням поточних даних. Отримання адекватних моделей $є$ необхідною умовою прогнозу- вання майбутніх процесів. Формально отримаємо банк моделей для одного показника ефективності.

$$
P_{i} \rightarrow M B_{i}=<H_{i}^{1}, H_{i}^{2}, \ldots, H_{i}^{w}>=M B_{i}\left(t_{0}, t_{1}, \ldots, t_{v-1}>,\right.
$$

де $t_{v-1}-$ час попередньої транзакції.

Серед моделей $H_{i}^{j}$ обираємо найкращу за критерієм

$$
\min _{j}\left|H_{i}^{j}\left(t_{v}\right)-P_{i}\left(t_{v}\right)\right| \text {, }
$$

де $H_{i}^{j}\left(t_{v}\right)$ - значення показника, розраховане 3 використанням j-ї моделі для часу останньої транзакції, $P_{i}\left(t_{v}\right)$ - відоме значення показника ефективності. Процес отримання моде-

$$
\min _{j} \sum_{l=0}^{r-1}\left|H_{i}^{j}\left(t_{v-l}\right)-P_{i}\left(t_{v-l}\right)\right|,
$$

де $r$ - потужність множини транзакцій для визначення найкращої моделі.

Існує ще одна проблема, пов'язана з обробкою бази даних. Оскільки кількість змінних в (2) досить велика, для рішення наступних задач існує необхідність їх скорочення без суттєвого зменшення інформативності. Одна $з$ таких задач полягає в пошуку характеристик діяльності підприємства або декількох підприємств, значення яких найбільш суттєво впливають на деяку характеристику підприємства, що розглядається. На початковому етапі припустимо, що такий вплив можливо представити лінійною функцією і характеризувати коефіцієнтом кореляції. Задача формується таким чином. Для кожного $k$-го показника ефективності $i$-го підприємства знайти $r_{i j}^{k l}-$ коефіцієнт кореляції 3 l-м показником ефективності $j$-ї системи, виконати аналіз отриманих результатів шляхом визначення порогового значення $r_{\text {th }}$ i обробка показників ефективності, для яких $\left|r_{i j}^{k l}\right|>r_{t h}$, які і будемо вважати інформативними.

Для розрахунку коефіцієнтів кореляції використовуємо елементи технології OLAP. Оскільки $D B_{2}$ містить дані про транзакції всіх підприємств, то необхідно сформувати лей (7) може бути модифікований за рахунок врахування транзакції до моментів часу $t_{v-2}, t_{v-3}$ та ін., в свою чергу, (8) запишеться в такому вигляді:

нову таблицю $D B_{3}$, Перший стовпчик якої буде містити дані про моменти часу, піч час яких відбуваються зміни показника ефективності $P_{i}^{k}$, другий стовпчик - значення $P_{i}^{k}$, в третьому стовпчику - значення $P_{1}^{1}$ в момент часу, попередній часу в стовпчику 1 , далі аналогічно і в останньому стовпчику будуть міститись значення останнього показника ефективності останнього підприємства в момент часу, попередній часу зміни $P_{i}^{k}$. Розрахунок коефіцієнтів кореляції для даних 3 таблиці $D B_{3}$ дозволить виділити характеристики, що здійснюють найбільший вплив на значення $P_{i}^{k}$. Зазначимо, що тут в якості часового лага впливу зазначена одиниця. В залежності від специфіки виробництва лаг може бути більшим одиниці, що значно збільшує розмірність матриці для пошуку коефіцієнтів парної кореляції.

Значення показника ефективності $P_{i}^{k}$ в переважній більшості випадків залежить від його значень в попередні моменти часу. Задача визначення такого часового лага $є$ супутньою, аналогічною попередній. Її рішення дозволить доповнити множину незалежних факторів моделі. Сама модель має вигляд:

$$
P_{i}^{k}\left(t_{v}\right)=G\left(P_{i}^{k}\left(t_{v}\right), P_{i}^{k}\left(t_{v-1}\right), \ldots, P_{i}^{k}\left(t_{v-l}\right), M\left(t_{v-1}\right), t_{v}\right) \text {, }
$$


де $l$ - часовий лаг обліку попередніх значень показника ефективності $P_{i}^{k}, M\left(t_{v-1}\right)$ - значення множини інформаційних показників ефективності інших систем.

Моделі прийняття рішень і оптимізація показників підприсмства

Рішення задач (8) - (10) створює базис для процесів прийняття рішень. Оскільки відомі ретроспективна інформація, поточний стан підприємства, закони його функціонування і прогноз значень показників ефективності при незмінних умовах і значеннях вхід- них факторів, то рішення можуть прийматися виходячи 3 відомих, заздалегідь сформульованих правил. В той же час, для отримання найкращих або прийнятних значень на множині можливих задач, структур виготовлення або стратегій управління, необхідно вирішити оптимізаційні задачі.

Як показано на рис. 1, кожний агент має свою базу знань, основну частину якої складають продукційні правила. В загальному випадку правила мають такий вигляд:

$$
\begin{aligned}
& \text { Якщ̧о }\left[P_{1}^{1}\left(t_{n}\right) \in D_{1 n}^{11} \& P_{1}^{1}\left(t_{H}\right) \in D_{1 н}^{11} \& P_{1}^{1}\left(t_{\sigma}\right) \in D_{1 \sigma}^{11} \& \ldots P_{1}^{l}\left(t_{n}\right) \in D_{1 n}^{l 1} \& P_{1}^{l}\left(t_{H}\right) \in D_{1 н}^{l 1} \& P_{1}^{l}\left(t_{\sigma}\right) \in D_{1 \sigma}^{l 1}\right. \text {, } \\
& i \quad P_{2}^{1}\left(t_{n}\right) \in D_{2 n}^{11} \& P_{2}^{1}\left(t_{H}\right) \in D_{2 \mu}^{11} \& P_{1}^{1}\left(t_{\sigma}\right) \in D_{2 \sigma}^{11} \& \ldots P_{2}^{l}\left(t_{n}\right) \in D_{2 n}^{l 1} \& P_{2}^{l}\left(t_{H}\right) \in D_{2 \mu}^{l 1} \& P_{2}^{l}\left(t_{\sigma}\right) \in D_{2 \sigma}^{l 1} \text {, } \\
& \left.i \quad P_{n}^{1}\left(t_{n}\right) \in D_{n n}^{11} \& P_{n}^{1}\left(t_{H}\right) \in D_{n H}^{11} \& P_{n}^{1}\left(t_{\sigma}\right) \in D_{n \sigma}^{11} \& \ldots P_{n}^{l}\left(t_{n}\right) \in D_{n n}^{l 1} \& P_{n}^{l}\left(t_{H}\right) \in D_{n \mu}^{l 1} \& P_{n}^{l}\left(t_{\sigma}\right) \in D_{n \sigma}^{l 1}\right] \text {, }
\end{aligned}
$$$$
m o\{p \& c \& s\}_{1} \text {; }
$$$$
\text { якщ̧о }\left[P_{1}^{1}\left(t_{n}\right) \in D_{1 n}^{12} \& P_{1}^{1}\left(t_{H}\right) \in D_{1 \mu}^{12} \& P_{1}^{1}\left(t_{\sigma}\right) \in D_{1 \sigma}^{12} \& \ldots P_{1}^{l}\left(t_{n}\right) \in D_{1 n}^{l 2} \& P_{1}^{l}\left(t_{H}\right) \in D_{1 \mu}^{l 2} \& P_{1}^{l}\left(t_{\sigma}\right) \in D_{1 \sigma}^{l 2}\right. \text {, }
$$$$
i \quad P_{2}^{1}\left(t_{n}\right) \in D_{2 n}^{12} \& P_{2}^{1}\left(t_{\mu}\right) \in D_{2 \mu}^{12} \& P_{1}^{1}\left(t_{\sigma}\right) \in D_{2 \sigma}^{12} \& \ldots P_{2}^{l}\left(t_{n}\right) \in D_{2 n}^{l 2} \& P_{2}^{l}\left(t_{H}\right) \in D_{2 \mu}^{l 2} \& P_{2}^{l}\left(t_{\sigma}\right) \in D_{2 \sigma}^{l 2} \text {, }
$$$$
\left.i \quad P_{n}^{1}\left(t_{n}\right) \in D_{n n}^{12} \& P_{n}^{1}\left(t_{H}\right) \in D_{n \mu}^{12} \& P_{n}^{1}\left(t_{\sigma}\right) \in D_{n \sigma}^{12} \& \ldots P_{n}^{l}\left(t_{n}\right) \in D_{n n}^{l 2} \& P_{n}^{l}\left(t_{H}\right) \in D_{n \mu}^{l 2} \& P_{n}^{l}\left(t_{\sigma}\right) \in D_{n \sigma}^{l 2}\right] \text {, }
$$
$m o\{p \& c \& s\}_{2}$;

$$
\begin{aligned}
& \text { якщчо }\left[P_{1}^{1}\left(t_{n}\right) \in D_{1 n}^{1 b} \& P_{1}^{1}\left(t_{\mu}\right) \in D_{1 н}^{1 b} \& P_{1}^{1}\left(t_{\sigma}\right) \in D_{1 \sigma}^{1 b} \& \ldots P_{1}^{l}\left(t_{n}\right) \in D_{1 n}^{l b} \& P_{1}^{l}\left(t_{H}\right) \in D_{1 \mu}^{l b} \& P_{1}^{l}\left(t_{\sigma}\right) \in D_{1 \sigma}^{l b}\right. \text {, } \\
& i \quad P_{2}^{1}\left(t_{n}\right) \in D_{2 n}^{1 b} \& P_{2}^{1}\left(t_{H}\right) \in D_{2 \mu}^{1 b} \& P_{1}^{1}\left(t_{\sigma}\right) \in D_{2 \sigma}^{1 b} \& \ldots P_{2}^{l}\left(t_{n}\right) \in D_{2 n}^{l b} \& P_{2}^{l}\left(t_{H}\right) \in D_{2 \mu}^{l b} \& P_{2}^{l}\left(t_{\sigma}\right) \in D_{2 \sigma}^{l b} \text {, } \\
& \left.i \quad P_{n}^{1}\left(t_{n}\right) \in D_{n n}^{1 b} \& P_{n}^{1}\left(t_{H}\right) \in D_{n \mu}^{1 b} \& P_{n}^{1}\left(t_{\sigma}\right) \in D_{n \sigma}^{1 b} \& \ldots P_{n}^{l}\left(t_{n}\right) \in D_{n n}^{l b} \& P_{n}^{l}\left(t_{H}\right) \in D_{n \mu}^{l b} \& P_{n}^{l}\left(t_{\sigma}\right) \in D_{n \sigma}^{l b}\right] \text {, } \\
& m o\{p \& c \& s\}_{b} \text {, } \\
& \text { або в наступній формі } \\
& \bigvee_{i=1}^{b} \boldsymbol{\bigotimes}_{j=1}^{n} \boldsymbol{\bigotimes}_{k=1}^{l}\left[P_{j}^{k}\left(t_{n}\right) \in D_{j n}^{k i} \& P_{j}^{k}\left(t_{H}\right) \in D_{j H}^{k i} \& P_{j}^{k}\left(t_{\sigma}\right) \in D_{j \sigma}^{k i}\right]
\end{aligned}
$$

де $b$ - кількість можливих змін множини задач, структур і стратегій управління, $n$ - кількість підприємств галузі, $t_{n}$ - час минулої транзакції, $t_{\mathrm{H}}-$ теперішній час (час щойно виконаної транзакції), $t_{\text {б }}$ - час наступної транзакції, $P_{i}^{k}\left(t_{n}\right)$ - значення $k$-го показника $i$-го підприємства в минулому, $P_{i}^{k}\left(t_{\mathrm{H}}\right)$ - поточне значення, $P_{i}^{k}\left(t_{\sigma}\right)$ - прогнозоване значення, $D_{j n}^{k i}, D_{j \mathrm{H}}^{k i}, D_{j \sigma}^{k i}$ - значення, або інтервали значень, або нечіткі множини 3 відповідними функціями належності для $j$-го варіанта $k$-го показника ефективності $і$-го підприємства в минулому, поточному і майбутньому.

Моделі (11) дозволяють модифікувати множини задач або структуру, або стратегію управління підприємством, виходячи 3 наперед жорстко зазначених правил.

В той же час, ОПР цікавить рішення задачі визначення оптимальних показників виробництва, коли відомі прогнозовані значення показників ефективності при змінних зовнішніх та інших умовах. В якості вихідних даних тут виступають ідентифіковані моделі (10). 
Необхідно виконати їх оптимізацію та знайти значення вхідних факторів, внутрішніх параметрів, що відповідають оптимальним значенням показників ефективності. Оскільки функції (10) можуть бути поліекстремальними, недиференційованими, заданими алгоритмічно або представленими нейромережею, тоді для отримання їх оптимуму раціонально використовувати еволюційні технології, а, враховуючи розмірність задачі, застосувати метод EvoMax [10], основою якого є еволюційна стратегія 3 керованим процесом випадкового пошуку кращих рішень. Такі рішення дозволяють змінювати поточні параметри діяльності підприємства і оптимізувати його показник ефективності.

\section{Висновки}

Використання МАС для аналізу і оптимізації діяльності підприємства галузі є новим підходом, в основу якого покладено дуалізм взаємодії таких підприємств і функціонування агентів системи. Подібно природній еволюції і еволюційним методам оптимізації розглянутий дуалізм визначає синтергетичний ефект від моделювання МАC як програмноаналітичної платформи рішення прикладних задач. Якість результатів, значною мірою, визначається вмінням системного аналітика, його знанням процесів функціонування економічних систем і побудову математичних моделей економічних процесів. Також необхідно вирішувати задачу мультикритеріальної оптимізації показників ефективності підприємства і визначення інтегрального критерія ефективності.

\section{Список літератури}

1. Снитюк В. Е. Мультиагентные технологии анализа и оптимизации функционирования предприятий отрасли. Математичні машини $і$ системи. 2015. № 2. C. 139-146.

2. Voloshyn O. Intellectual information support of branch enterprise executives' decision making processes. Information Theories and Applications: International Journal. 2014. Vol. 21, Number 4. P. 303313.

3. Luck M. Multi-Agent Systems and Applications. Springer-Verlag: Berlin, 2001. $452 \mathrm{p}$.

4. Highlights on Practical Applications of Agents and Multi-Agent Systems.
Proceedings of International Workshops of PAAMS 2013, Salamanca, Spain, May 22 24, 2013.

5. Гужва В. М. Моделювання мультиагентних систем для управління логістичними процессами на підприємствах: автореф. дис... канд. екон.наук: 08.03.02. К., 2002. $17 \mathrm{c}$.

6. Крицкий А. В. Информационная система поддержки принятия решений на основе мультиагентного похода: дисс... канд. техн. наук : 05.13.01. Екатеринбург, 2007. $150 \mathrm{c}$.

7. Єршов С. В. Теоретичні основи моделеорієнтованої побудови нечітких інтелектуальних мультиагентних систем: автореф. дис. докт. фіз.-мат. наук 01.05.03. К., 2013. 36 c.

8. Нарожний О. В. Моделі інтелектуального управління процесом навчання за допомогою мультиагентних систем: автореф. дис... канд. техн. наук. 05.13.23. Одеса, 2007. 19 c.

9. Скворцов І. Б., Гудзь О. І., Швед Л. Р. Планування обсягів виробництва продукції на промисловому підприємстві з урахуванням іiі життєвого циклу. Науковий вісник НГУ. №6. Дніпро, 2013. С. 132 137.

10. Снитюк В. Є. Спрямована оптимізація i особливості еволюційної генерації потенційних розв'язків. Матеріали Міжн. школи-семінару «Теорія прийняття рішень»: Ужгород (1-6 жовтня 2012). C. $182-183$.

\section{References}

1. Snutyk, V. E. (2015) Multiagent Analysis and Optimization of Enterprise' Activity Processing. Mathematical Electronik and Systems. №2, p. 139-146.

2. Voloshyn, O. (2014) Intellectual Information Support of Branch Enterprise Executives' Decision Making Processes. International Journal "Information Theories and Applications”. Vol. 21, Number 4, pp. 303313.

3. Luck, M. (2001) Multi-Agent Systems and Applications. Springer-Verlag: Berlin, 452 p.

4. Proceedings of International Workshops of PAAMS 2013 (2013) Highlights on Practical Applications of Agents and Multi-Agent Systems. Salamanca, Spain. May 22-24. 
5. Huzhva, V. M. (2002) Multiagent Systems' Modeling for Enterprise' Logistic Process Management: abstr. Dissertation MSc: 08.03.02. Kyiv, pp. 17.

6. Krytzky, A. V. (2007) Informational Expert Support System based on multiagent Approach: Dissertation MSc: 05.13.01. Ekaterinburg, $150 \mathrm{p}$.

7. Yershov, S. V. (2013) Theoretical building basis of the modeloriented obscure intellectual multiagent systems. Dissertation. MSc 01.05.03. Kyiv, 36 p.
8. Narozhny, O. V. (2007) Schoolling Process Intellectual Management Models based on Multiagent System: abstr. Dissertation MSc. 05.13.23. Odessa, 19 p.

9. Skvorzov, I. B., Hudz, O. I., Shved, L. R. (2013) Industry output planning considering its cycle. Science Bulletin NSU №6, Dnipro, pp. 132-137.

10. Snutyk, V. E. (2012) Directed Optimization and Peculiarities of Potential Resolve. Abstr. International school-lecture «Make Decision Theory»: Uzhhorod (1-6 October 2012), pp. 182-183.

B. V. Mysnyk, senior lecturer, e-mail: setne1985@gmail.com.

T. I. Veretil'nyk, Ph.D., associate professor, e-mail: vertim@mail.ua

L. D. Mysnyk, Ph.D., associate professor, e-mail: l.mysnyk@chdtu.edu.ua

Cherkasy state technological university

Bul. Shevchenko, 460, Cherkasy, 18006, Ukrainian

\section{MULTI-AGENT FUNCTIONING OPTIMIZATION AND DECISION MAKING ASSISTANCE FOR PRINTING TRADES AREA HEAD}

The problem of analyzing and optimizing the sector enterprise functioning is considered. Proposed as modeling tools and decision support systems use multi-agent technology. Identify the problems that accompany the modeling process, models with production rules and developed a method of optimization based on changes in a variety of tasks, production, and enterprise management strategies.

Keywords: sector enterprise, decision making, multi-agent technologies.

Стаття надійшла 21.05.2018.

Рецензенти: В. I. Осипенко, д.т.н., професор,

С. В. Поздєєв, д.т.н., професор. 